\title{
User-centred design of a portable fire extinguisher
}

\section{Ergonomics in Design}

AUTHORS: Mary Amos, Dr Glyn Lawson

FEATURE AT A GLANCE: This case study documents the process followed to produce an alternative

design of fire extinguisher. The work focuses on how informative data can be gathered for an ethically challenging product scenario through the use of a range of user-centred research methods, including: literature review; product evaluation; shadowing study; empathy study; expert interview; focus groups; and simulation equipment.

Design improvements as a consequence of this process include: reductions in size and weight; refillable cartridges; single-handed operation; intuitive form; minimal clean up post-use; and better portability.

KEYWORDS: Fire extinguisher, user-centred design, ergonomics, industrial design, user testing, design process.

\section{Introduction}

Fire extinguishers are widespread safety devices used to extinguish small fires. To fulfil EU safety regulations they must be installed in all public buildings. Despite this, the intended user (the general public) often does not understand how a fire extinguisher functions; neither can they differentiate between the different kinds, which can lead to mistakes in use. Compounding this problem are the costs of maintaining and refilling a typical fire extinguisher, which lead to the discouragement of users from interacting with the device unless in a real emergency, by which time familiarity would be a real advantage. Moreover, the lack of regulations in the domestic context means fire extinguishers are overlooked as an essential utility product within the home.

This paper describes the redesign of an emergency product and the process of defining the requirements of end users with limitations (e.g., the elderly) to increase the product's usability, functionality and reliability. Thus, this approach differs from more traditional attempts to accommodate the majority of users. In this case, ensuring product usability for user groups with the most limitations would virtually guarantee its viability for all users (e.g., 'universal design'). This case study explores how user-centred research can inform the redesign of the portable fire extinguisher. The project was completed by a Product Design final year MEng student, from The University of Nottingham (UK), who developed a concept that is intuitive, refillable, and compact. This article presents the variety of research methods used in the design process, and concludes with a proposed concept for a portable fire extinguisher design. 


\section{Problems with the existing design}

In the United Kingdom there are currently six types of fire extinguisher that cater for various types of fire, as no one fire extinguisher can fight all fires effectively. The internal substance contained within the extinguisher is called a suppressing agent. The four types of suppressing agents commonly found in public buildings use water, foam, dry powder and $\mathrm{CO}_{2}$; specialist fire extinguishers not available to the general public use wet chemical and halon gas. This study will focus on the four suppressing agents suitable for public use without specialist training.

Dry powder represents the widest application with the ability to fight solids, flammable liquids, flammable gases and electrical fires. However, it causes significant damage to property when discharged, in the form of settling powder which can damage fabrics, electronics and machinery. The current system of matching extinguisher type and suppressing agent to fire type is regulatory in nature and not familiar to the average consumer.

As an important safety device, the methods used to protect fire extinguishers from misuse often have the contradictory effect of making them hard to use. Tamper tags and costly fines represent the most common methods of discouraging inappropriate use. With tamper tags, the lever mechanism is barred, either by a metal pin or a plastic ring. This is deliberately difficult to remove, even for the able-bodied user. Penalties for use can also discourage users, even in emergency situations.

Another issue with existing devices is that fire extinguishers are not common domestic utility products. While the Fire and Rescue Services encourage a 'get out and stay out' policy regarding domestic fires (FETA, 2001) statistics suggest that $78 \%$ of fires in the UK are extinguished without the Fire and Rescue Service's intervention (Kobes, 2010). Thus, the desire to protect family and property on discovery of a fire is evidently a basis on which to explore domestic and portable fire extinguishers.

\section{Design Process}

It is significant that involvement or consideration of users in a design process can lead to a higher quality product and better match to user needs (Wilson and Sharples, 2015). However, when considering the design process for a fire extinguisher, the ethical tenant of safety of research participants had to be at the forefront of the chosen methodology. Therefore, the adopted research methods listed below emphasise theoretical research, advice from professionals and controlled environments during practical research. The methods encompass the following:

Literature Review

Product Evaluation

Shadowing Study

Fire Awareness Training 
Interview with an Expert

Focus Group

Simulation/Empathy Gloves

The application of each method and its contribution to the design is described in the following sections.

\section{Literature Review}

Current research in the field was reviewed to inform and focus the redesign process. Articles with the keywords Fire, Fire Extinguisher, Human behaviour, Fire Safety and Human Factors were used to identify the key issues that inhibit human interaction with fire safety equipment. Patterns emerged as to what problems the redesign needed to address. The results of the literature review are summarised below:

- Statistics and studies confirmed that people do tackle small scale fires despite the official 'get out and stay out' policy (FETA, 2001; Kobes, 2010). 78\% of domestic fire incidents in the UK are handled without Fire and Rescue Services' intervention (Kobes, 2010).

- Fire safety information needs to be conveyed frequently or repetitively for it to become familiar (Subramaniam, 2004).

- It is optimistic to expect untrained people to be 'competent at weighing their options before engaging in proper [fire fighting] actions' (BRE, 1993; Fahy, 2009; Huseyin, 2006).

- Existing fire extinguishers exclude certain demographics. For example, '22\% of the elderly [are] unable to break the safety tag' (Bruck, 2010). An extinguisher requires twohanded operation and therefore excludes users who are not able-bodied.

The findings emphasised that a redesign of current fire extinguishers is required to make them user-friendly in the domestic context. As a direct consequence of the literature review, a focus group was organised to explore the needs of the elderly in operating a domestic fire safety device.

\section{Product Evaluation}

A product evaluation was conducted to give the designer personal experience in the use of existing devices. A $2 \mathrm{~kg}$ dry powder fire extinguisher was selected to test as part of the product evaluation. The dry powder extinguisher has the broadest application when fighting fires, being able to extinguish solids, flammable liquids, flammable gases and electrical fires. This ensured the fire could be put out but it also allowed the test to exhibit the major drawback of the dry powder design, namely, the large amounts of residue post-fire that can damage property.

The designer had no prior experience interacting with a fire extinguisher. She was therefore able to experience the product as a typical user. Even with no training or prior instruction (a 
situation similar to the target demographic) she was able to extinguish a small controlled fire which was ignited using a cardboard box approximately the size of a wastepaper basket.

The activity was not intended to replicate an emergency situation, as the controlled situation meant the cognitive and emotional issues of confronting a fire in the home did not apply. However, it provided the designer with a firsthand account of the current fire extinguisher model in use.

This exercise was video recorded for further analysis and documentation. One finding of this test was that an able-bodied person found the extinguisher to be heavy. When full, it weighed $3.5 \mathrm{~kg}$; this weight may restrict users who are unable to lift and operate such a load. Another observation was that the designer was unsure of the pressure to apply to the handle to discharge the extinguisher, and that the power of the device on discharging was enough to unbalance them. It was noted that, as expected, large amounts of powder were released, which stained the designer's clothing and settled on the surrounding area. The powder also negatively affected visibility (Fig. 1).

One aim was clear: reduce the weight of the extinguisher during the redesign. Another was to use a suppressing agent that could douse a majority of domestic fires while also ensuring property was not damaged further by the use of a fire extinguisher. An alternative suppressant could also be selected to reduce the visibility issues associated with dry powder. The fire was extinguished without using the full capacity of the extinguisher. Therefore, a smaller capacity than $2 \mathrm{~kg}$ would reduce weight while also being capable of dousing a small domestic fire.

\section{Shadowing Study}

A Fire Extinguisher Maintenance worker was shadowed so that the designer could obtain information about the maintenance of extinguishers in public buildings and the legal regulations that govern the use of such devices (Fig. 2). Following the worker in his role, the designer was able to 'experience the situations of his or her daily life or work in parallel with them, collecting insights through the real nuance of first-hand, real-time exposure' (Martin \& Hanington, 2012).

The maintenance checks were thorough and the records for extinguishers in public environments were extensive. No comparable process exists in private residential dwellings. The methods used to deter improper use were also clarified. For example, adding to safety tags and tamper tags discussed above, are fire jackets and fire boxes, which are coverings that deter use by making the extinguisher less readily accessible. The ubiquity of these methods of deterrence emphasised the need to consider potential misuse during the redesign and to prevent any harm by accidental activation.

It was the opinion of the expert that extinguishers are only situated in public places to fulfil legislation. The public are not encouraged to use them, again highlighting the contradiction of 
official 'get out and stay out' policies and the mandatory presence of fire extinguishers in public buildings.

Fire Awareness Training

To further inform the design process, a one day Fire Awareness Training Course run by South Yorkshire Fire and Rescue Service was completed. The Realistic Fire Training Building (RFTB) immerses the trainee in a realistic fire simulation and was the most valuable experience of the course. Similar to an empathy study, the RFTB allowed a 'deep approximation of environmental conditions, forging an empathic sense of real-life user experiences' (Martin \& Hanington, 2012).

The activity helped the designer identify the need for an intuitive design with simple instructions that would translate to better performance in high-stress situations. The RFTB also provided an appreciation of how quickly fires can escalate (Fig. 3).

The Fire Awareness course also discussed the theory of fire behaviour and combustion; user behaviour (how people react in fire scenarios and interact with others around them); extinguisher coverage and timing (what size extinguisher is the most appropriate for different contexts); and different types of fires (different extinguishing options for the size/seriousness of the fire).

The designer activated and interacted with all publicly available classes of fire extinguisher. Foam and dry powder left messy residue; water was not as messy but can be dangerous if used on the wrong class of fire, as it conducts electricity. $\mathrm{CO}_{2}$ did not leave any residue and does not conduct electricity, but makes a loud noise when activated. This exercise allowed the designer to compare first-hand the different suppressing agents.

\section{Expert Interview}

To conclude the initial research element, an interview was arranged with a Fire Safety Officer with several decades of experience in the fire safety industry who has worked as both a Firefighter and a Hazmat Officer. An informal interview supported many of the findings from previous activities, and revealed the following:

the elderly, young and disabled are the most at risk, and therefore ensuring the redesign encourages inclusivity is important

fire can spread rapidly and become very serious within a number of minutes maintenance might be an issue associated with ownership of an extinguisher, therefore the design would need to encourage regular checks/ interaction to encourage maintenance

aesthetics would be important for fire extinguishers in a domestic context portability and accessibility are of high importance and would need to be considered in the ergonomics of the new design. 
A key point made during the interview was that there can be no guarantee of safety with the use of an extinguisher. This being the case, the user gets involved at their own risk.

\section{Initial Concepts}

Sketches and ideas were being produced in parallel with the research activities and the findings from the research informed a wide range of possible design solutions. The initial concepts varied from: retrofitted stand-alone sprinkler systems; a self-assembled educational kit; alternative form ideas; ceiling-mounted extinguisher systems; and a handheld extinguisher which achieved a reduction in overall size and weight (Fig. 4).

After conducting an internal evaluation of these concepts with peers, tutors and senior researchers, a second visit was arranged to discuss these ideas with the Fire Safety Officer. This feedback was used to decide which concepts to develop further.

It was decided to move forward with the handheld extinguisher concept. Compared with other concepts, the design of a smaller extinguisher seemed to have the potential to be valuable to a wider user group and presented the greatest opportunity for innovative design. While effective, ceiling mounted systems offered limited scope for user-centred design, selfassembled education systems could produce too many errors and encourage children to 'play' with fire and simply altering the form of the existing design would have limited applications in the domestic context.

The key areas of design development were reductions in size and weight and that the product be easy to activate and interact with. Working to these design objectives, the end concept would be an inclusive fire extinguisher, capable of being operated by the widest possible demographic.

During the concept analysis discussion with the Fire Safety Officer it was suggested to use $\mathrm{CO}_{2}$ as a suppressing agent, as it is suitable for electrical fires and is effective against other fire types. $\mathrm{CO}_{2}$ is a cleaner suppressant compared to dry powder or foam as it leaves no residue after use and therefore minimises the risk of damage to property. $\mathrm{CO}_{2}$ has several limitations (loud noise when operated, the possibilities of frostbite or suffocation, limitation in use on flammable solids, flammable gasses or cooking fat fires), but by limiting the amount of suppressing agent it is hoped that the noise would be reduced, as would the risk of suffocation. Ensuring that the extinguisher was designed to keep users' hands out of the way of the suppression agent would minimise the danger of frostbite.

Reducing the amount of suppressing agent was discussed with the expert as this would restrict the products use to 'small fires'. He reiterated a point made in the previous interview, that fires can escalate quickly and he would encourage users to evacuate the house if it was any bigger than a wastepaper basket. Therefore, limiting the suppressing agent would restrict the user as to the size of fire they were tackling. Due to the nature of $\mathrm{CO}_{2}$ and how the gas is designed to smother the fire, once the gas has floated away the fire may re-ignite. We 
discussed what the main aim of the extinguisher was: to extinguish the fire completely, or give the user extra time to escape the fire, which $\mathrm{CO}_{2}$ should do. The design was developed to incorporate smaller $\mathrm{CO}_{2}$ cartridges, which enabled the extinguisher to be refillable and compact.

\section{Focus Group}

To investigate the best solution for making the concept inclusive, a focus group was arranged with a group of elderly residents from a local retirement village for people in their sixties or older. There were five participants (three female, two male) who took part in the study and specific ages were not recorded. Information from the focus group was used to inform and support the next stage of development, as the group provided deep insights into the older demographic's views on the product and highlighted issues that had not yet been identified in the design process. Details of the focus group activities and responses can be found in Table B.

For example, they emphasised the importance of affordances (i.e. where the nozzle should be on blank foam models. Fig. 5) and how the product should be held. The group also confirmed information gathered early in the design process that current designs are unsuitable for the elderly. They were particularly worried about grip and hand strength when activating the extinguisher. Their response to the foam models highlighted the importance of an intuitive form to ensure correct interaction with the extinguisher.

\section{Simulation Gloves}

After the focus group, further developments were made to the form and activation method to ensure ease of use. To understand and analyse the proposed final form, Cambridge simulation gloves (Fig. 6) were used to simulate 'a reduction in the functional ability of the hands' (Inclusive design toolkit, 2015). The simulation gloves use plastic strips to limit the dexterity of the fingers, thumb and wrist of the designer, allowing empathy with the elderly. Using the simulation gloves accurately confirmed the comfort and location of the trigger in allowing high force exertion.

\section{Proposed Concept}

The proposed concept is a compact $\mathrm{CO}_{2}$ fire extinguisher designed for use in the domestic context (Fig. 7). The size reduction limits the product's use to small fires and is an indication that if the product does not extinguish the fire it is too big to tackle. Assembly, cost, manufacture, materials and production quantities were also considered in detail to ensure the new concept was realistic and achievable. 
The redesigned fire extinguisher has key features that were motivated by the findings of the literature review and the user-centred activities including:

- Reduced size and weight—making the product more inclusive (as a result of the findings from the product evaluations, and interviews with an expert and focus group).

- Refillable $\mathrm{CO}_{2}$ cartridges - removes the taboo that products can only be used in emergencies due to the expense of refill and maintenance (as a result from the findings of the shadowing study, expert interview and information gathered during the fire awareness training). It is hoped that by making it refillable users will interact with it more often, becoming familiar with its operation.

- Single-handed operation-more inclusive and simple to use, broadening the demographic of users who could operate the design (information gained from the interview with an expert, focus group, Cambridge simulation gloves).

- Intuitive form - the form indicates how the product should be held and is recognisable due to its similarity to other well-known and associated products, incorporating familiar affordances (a result of the focus group).

- Minimal clean-up post-use - the choice of suppressing agent $\left(\mathrm{CO}_{2}\right)$ means minimal cleaning is required after use. Often the risk of causing permanent damage to property and possessions makes users hesitate to use alternative fire extinguishers, such as dry powder extinguishers (as identified during the product evaluation and during the interview with an expert).

- Portable - the extinguisher was designed primarily with the domestic context in mind; however, its size does incorporate portability into the design. This could widen its application/context to cars, camping, caravans and many more. (Targeting the domestic context was encouraged by the findings of the literature review, interview with an expert and the shadowing study).

\section{Future Developments}

The next stage in the design process would be to produce a functioning prototype which would allow further testing and evaluation to confirm that the design is a viable improvement. Rigorous testing would be required to approve the types and size of fires that could be extinguished with the limited amount of $\mathrm{CO}_{2}$ and confirm that this is the most suitable suppressing agent. As the proposed design only reached concept stage, weight was not calculated, but the initial product evaluation conducted for the redesign indicated a total weight of $2 \mathrm{Kg}$ (when full). This would be a good target weight to be tested, and the force required to activate the trigger should be less than $15 \mathrm{Nm}$ (Imrhan, 1987) to satisfy the target demographics. Experts and participants of the focus groups would be revisited with a physical, functioning prototype to undertake usability tests and analyse the design for further 
improvements. Testing would also inform the design of the labeling and instructions on the product and allow further research on producing a maintenance/refill plan.

\section{Conclusion}

This paper has documented the process of defining requirements of end users to address the limitations of an existing product, in order to improve its functionality (e.g., behavioral viability) and the user experience. This is important, because safety and reliability represent compelling priorities for emergency interventions. However, further research is needed to provide an empirical behavioral profile of the redesigned product using functioning prototypes to demonstrate its feasibility and user acceptance. In conclusion, this project highlights the importance of a user-centered design process when designing equipment to be used in emergency situations, even though the ethics surrounding fire and fire studies make it difficult to do direct testing and research activities. In this case, a wide range of methods enabled a rich insight into the context and issues affecting fire extinguisher design. This paper proposes an improved concept for a portable $\mathrm{CO}_{2}$ fire extinguisher, and documents the activities which informed the design outcome.

\section{References}

BRE (Building Research Establishment) Digest, (1993) Human Behaviour in Fire. Digest 388. Watford: UK

Bruck, D., Thomas, I., (2010) Interactions Between Human Behaviour and Technology: Implications for Fire Safety Science. Fire Technology, Vol. 46, p769-787.

Fahy, R., Proulx, G., Aiman, L., (2009) 'Panic' and human behaviour in fire. In:Proceedings of the $4^{\text {th }}$ International Symposium on Human Behaviour in Fire. Cambridge, $13^{\text {th }}$ July 2009. Canada: National Research Council Canada.

FETA (Fire Extinguishing Trades Association), (2001) Fire Extinguishers (PFE) in the home, FETA News, Issue 27, October 2001, p2.

Huseyin, Satyen, (2006) Fire safety training: It's importance of enhancing fire safety knowledge and response to fire. The Australian Journal of Emergency Management, Vol. 21(4), p48-53.

Imrhan, S.N. (1994). Muscular Strength in the elderly - Implications for ergonomic design, International Journal of Industrial Ergonomics, 13, p125-138, cited in: Smith, S., Norris, B., Peebles, L. Older Adultdata (2000), Intitute for Occupational Ergonomics, Universtiy of Nottingham, Nottingham.

Inclusive Design Toolkit, (2015). Cambridge Simulation Gloves. [online] Available at: http://www.inclusivedesigntoolkit.com/betterdesign2/gloves/gloves.html [Accessed 18 Dec. 2016]. 
Kobes, M., Helsloot, I., Vries, B., Post, J., (2010) Building safety and human behaviour in fire: A literature review. Fire Safety Journal, Vol. 45, p1-11.

Martin, B., Hanington, b., (2012) Universal Methods of Design, United States of America: Rockport Publishers

Subramaniam, C., (2004) Human Factors influencing fire safety measures, Disaster Prevention and Management: An International Journal, Vol.13 (2), p110-116.

Wilson, J. R., Sharples, S. (2015). Methods in the understanding of human factors. In: J.R.Wilson and S.Sharples, Evaluation of Human Work, Fourth edition, CRC Press, Boca Raton, Florida, p1-32.

\section{Acknowledgements}

Copy editor: Fionn Coughlan-Wills

\section{AUTHOR BIOGRAPHIES}

Mary Amos is an Industrial Designer at G2 Innovation. Her primary interests are user-centred research methods, requirement analysis and user-driven development. She graduated with honours from the University of Nottingham with an MEng in Product Design and Manufacture.

Glyn Lawson is an Associate Professor, and member of the Human Factors Research Group, within the Faculty of Engineering at The University of Nottingham. His research interests include the human factors of advanced technologies for design and manufacturing applications. Glyn's background combines academia and industry, having previously worked as a Design Ergonomist for Jaguar Land Rover. 
Table A. Overview of current fire extinguisher agents, use and devices

\begin{tabular}{|l|l|l|}
\hline $\begin{array}{l}\text { Extinguisher Type, or } \\
\text { Suppressing Agent }\end{array}$ & Fire Type & Typical fire extinguisher \\
\hline Water & Solids (e.g. Wood, Plastic) & \\
\hline Foam & Solids, Flammable Liquids & \\
\hline
\end{tabular}




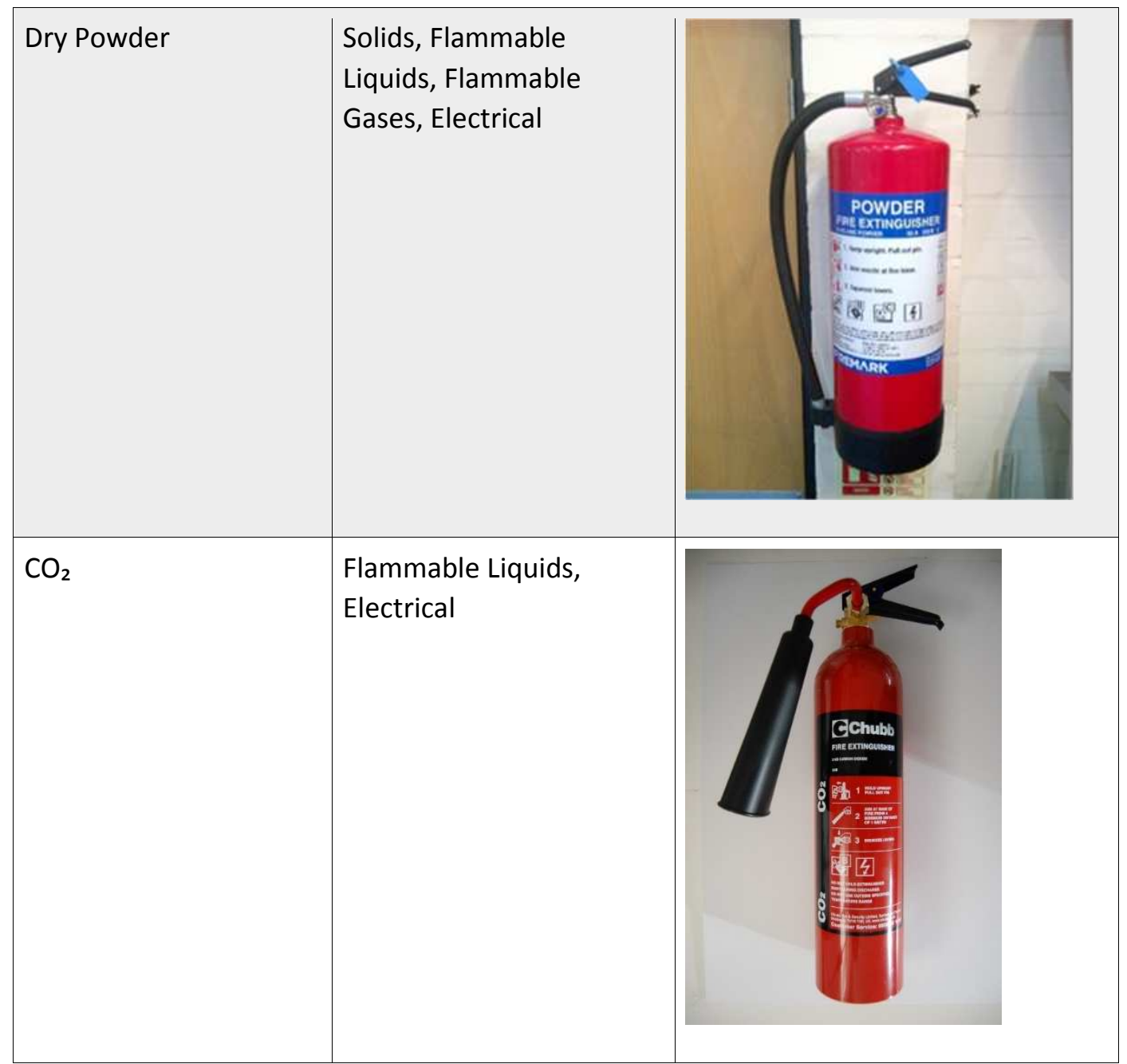

Table B. Overview of the focus group activities

\begin{tabular}{|l|l|l|l|}
\hline Activity & $\begin{array}{l}\text { Time } \\
\text { Allocated }\end{array}$ & Purpose of Activity & Response/Feedback/Implication \\
\hline Mindmap & 15 minutes & $\begin{array}{l}\text { Focus participants thoughts } \\
\text { on the topic of study and } \\
\text { identify: } \\
\begin{array}{l}\text { 1.Problems with existing } \\
\text { design } \\
\text { 2.Priority design features } \\
\text { and functions for the new } \\
\text { design }\end{array}\end{array}$ & $\begin{array}{l}\text { 1. weight (too heavy, potential to bash } \\
\text { side); specific models are needed for } \\
\text { specific locations; can't read instructions } \\
\text { without spectacles on; just gathers dust; } \\
\text { complicated to operate. } \\
\text { 2. Simple to operate; inherently safe; easy } \\
\text { to use; efficient (does its job); childproof; } \\
\text { lighter; appearance is important. }\end{array}$ \\
\hline
\end{tabular}




\begin{tabular}{|c|c|c|c|}
\hline $\begin{array}{l}\text { Visual } \\
\text { Concept } \\
\text { Discussion }\end{array}$ & 30 minutes & $\begin{array}{l}\text { Determine which aspects of } \\
\text { the different designs are } \\
\text { appealing to this particular } \\
\text { demographic and any issues } \\
\text { they would have using the } \\
\text { product. }\end{array}$ & $\begin{array}{l}\text { Some key points from the discussion: } \\
\text {-Reducing the size and weight makes it } \\
\text { more appealing and more likely to have } \\
\text { multiple units around the house. } \\
\text {-Prefer a portable design that can be taken } \\
\text { to the fire } \\
\text { - Want some degree of control over when } \\
\text { the extinguisher is activated and be able to } \\
\text { direct the suppression agent (don't want it } \\
\text { to automatically go off or be fixed in a static } \\
\text { position). } \\
\text { - Like the failsafe clip which prevents } \\
\text { accidental activation. }\end{array}$ \\
\hline $\begin{array}{l}\text { 3D Sketch } \\
\text { Models }\end{array}$ & 30 minutes & $\begin{array}{l}\text { Identify what forms are } \\
\text { intuitive to hold and the best } \\
\text { methods to activate the } \\
\text { extinguisher. }\end{array}$ & $\begin{array}{l}\text {-There needs to be an obvious orientation } \\
\text { of the product (suggesting asymmetric form } \\
\text { is preferred); needs to be intuitive. } \\
\text { - Needs to be obvious where the } \\
\text { suppression agent will come out of. } \\
\text {-Two handed operation can often be } \\
\text { difficult for elderly as often one hand is } \\
\text { stronger than the other. } \\
\text {-Thumb strength needs to be considered } \\
\text { when designing buttons. } \\
\text {-Don't want hand to be close to where the } \\
\text { suppression agent is going to come out of. }\end{array}$ \\
\hline
\end{tabular}



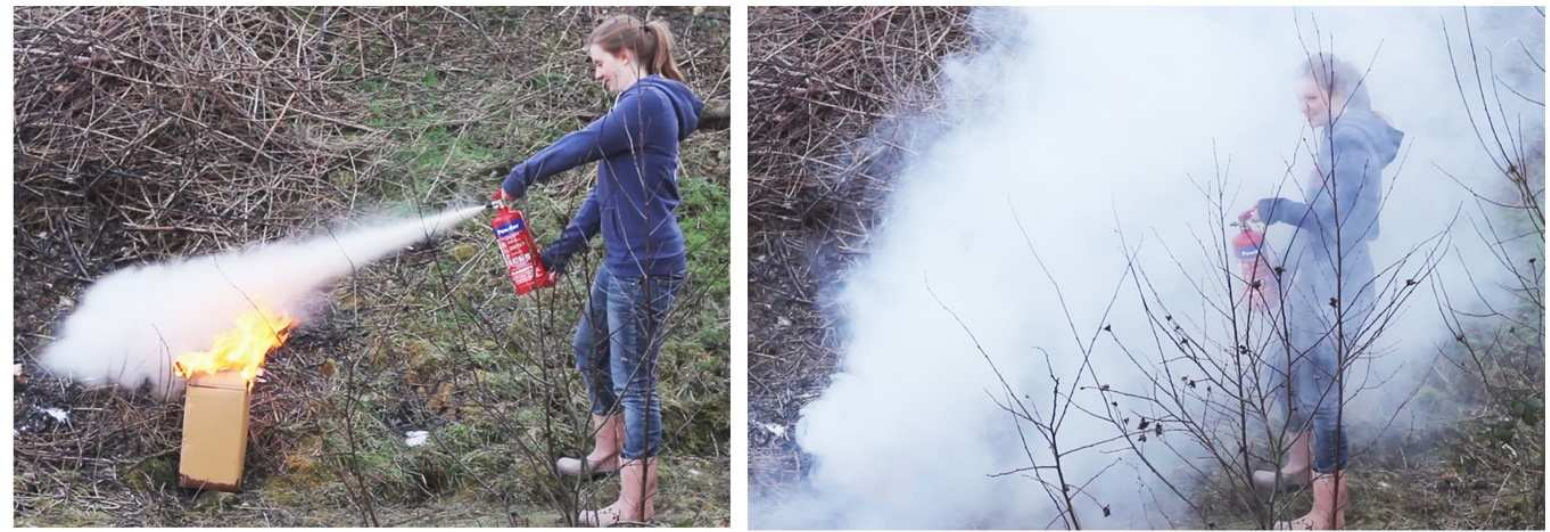

Figure 1. Product Evaluation- the extinguisher was more powerful than expected, and produced clouds of powder obscuring the participant's vision.

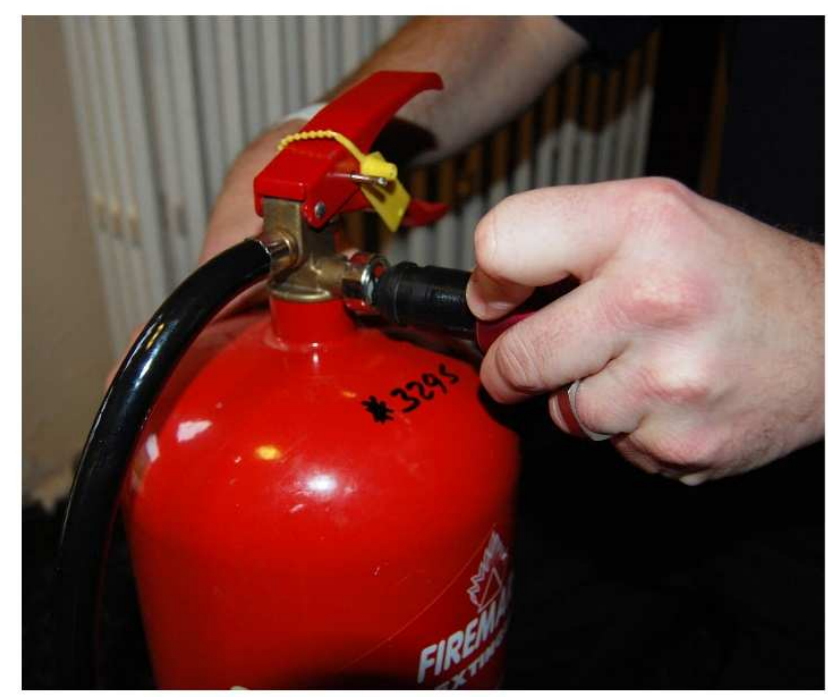

Figure 2. Shadowing Study- Observations of maintenance routines for the current design of Fire Extinguishers

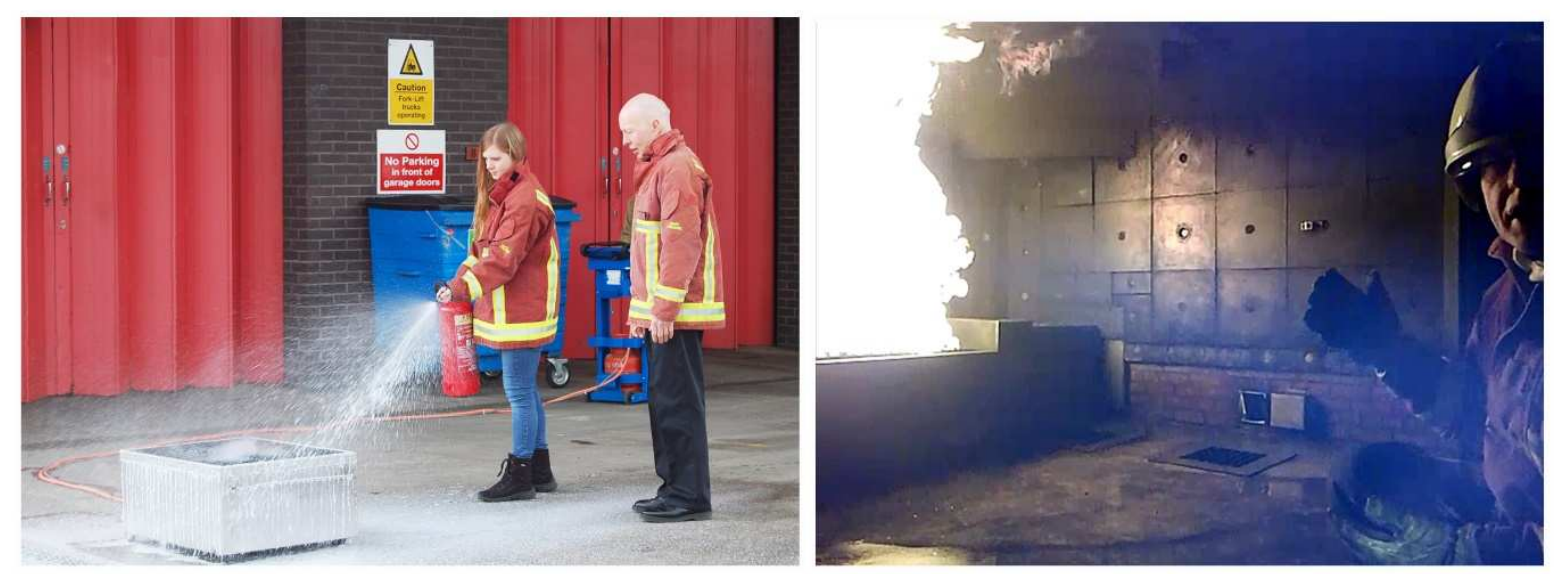

Figure 3. Fire Awareness Training- Practical training using an extinguisher and experiencing the Realistic fire training building (RFTB) 

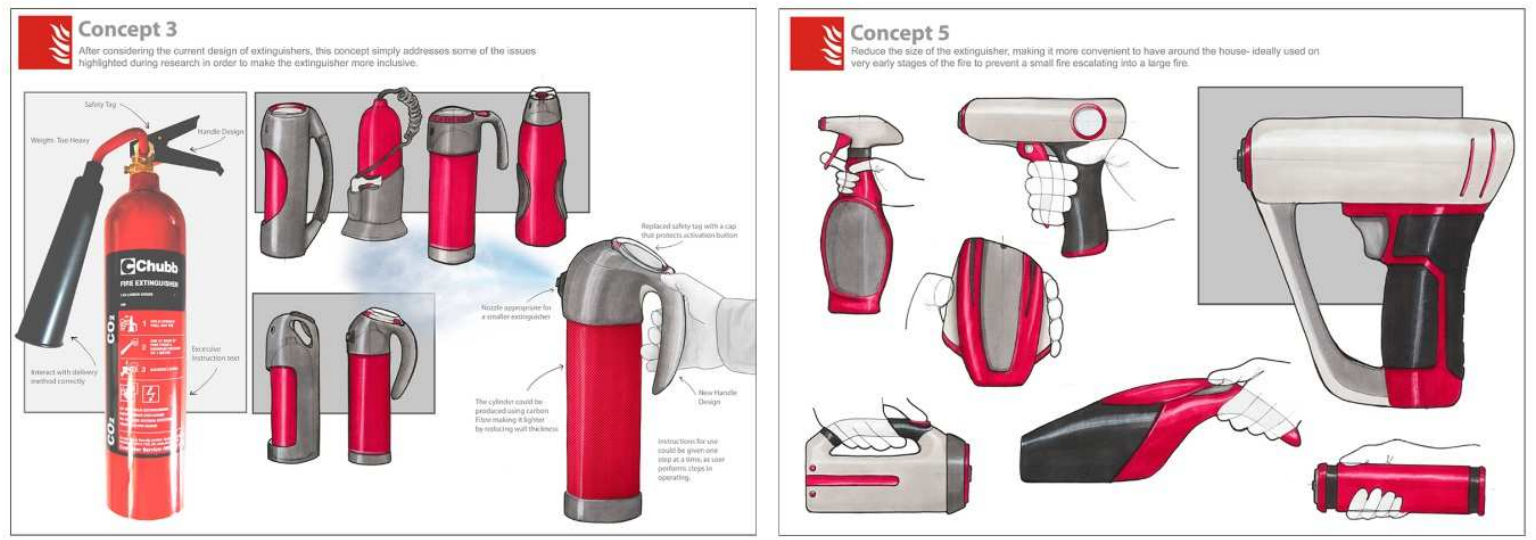

Figure 4. Interview with an expert- some of the concepts and visual prompts used during discussions with an expert.
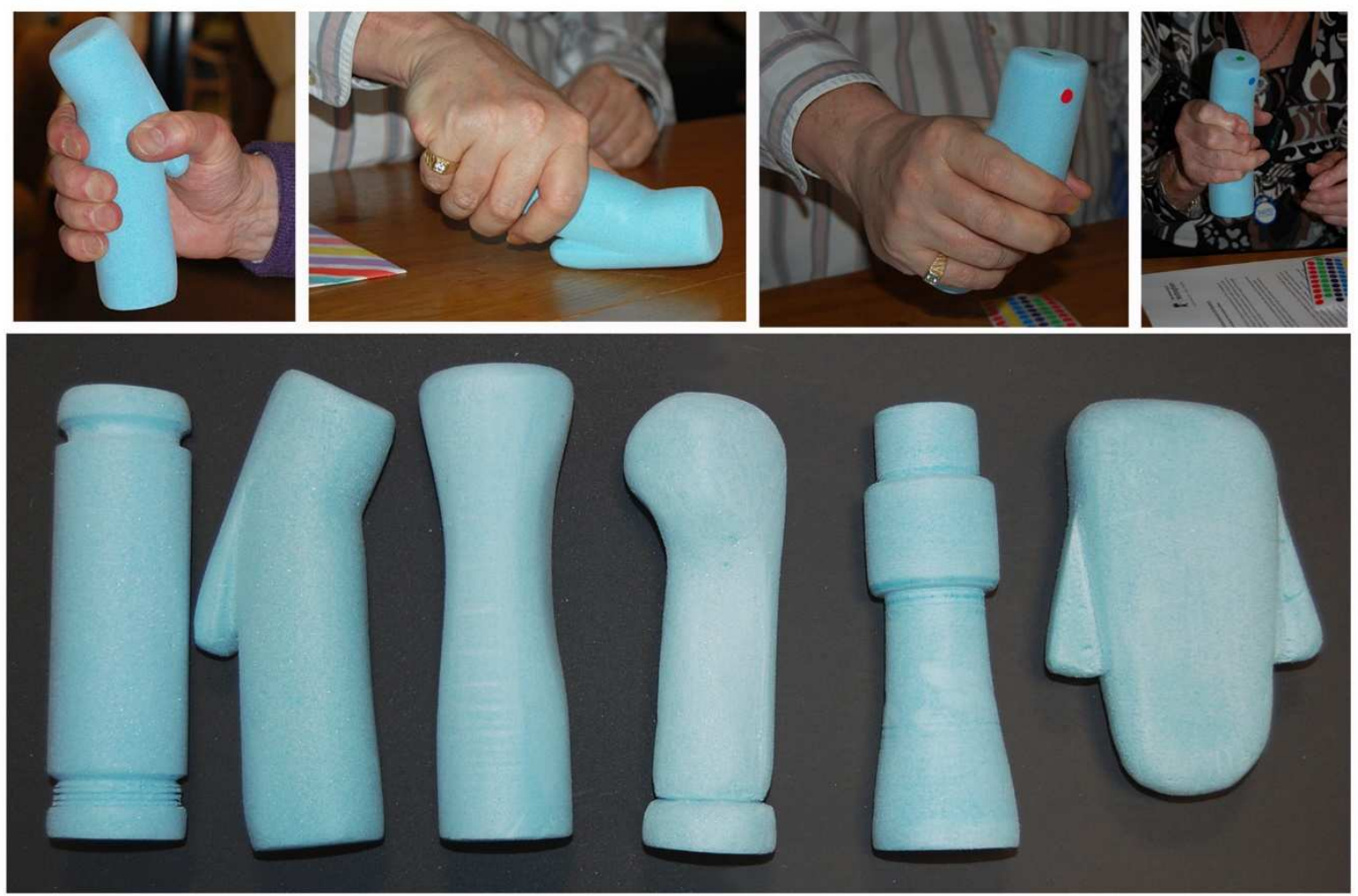

Figure 5. Focus Group- Participants were given the opportunity to hold and interact with Sketch models. The aim of this activity is to identify what forms are intuitive to hold and the best methods to activate the extinguisher. 

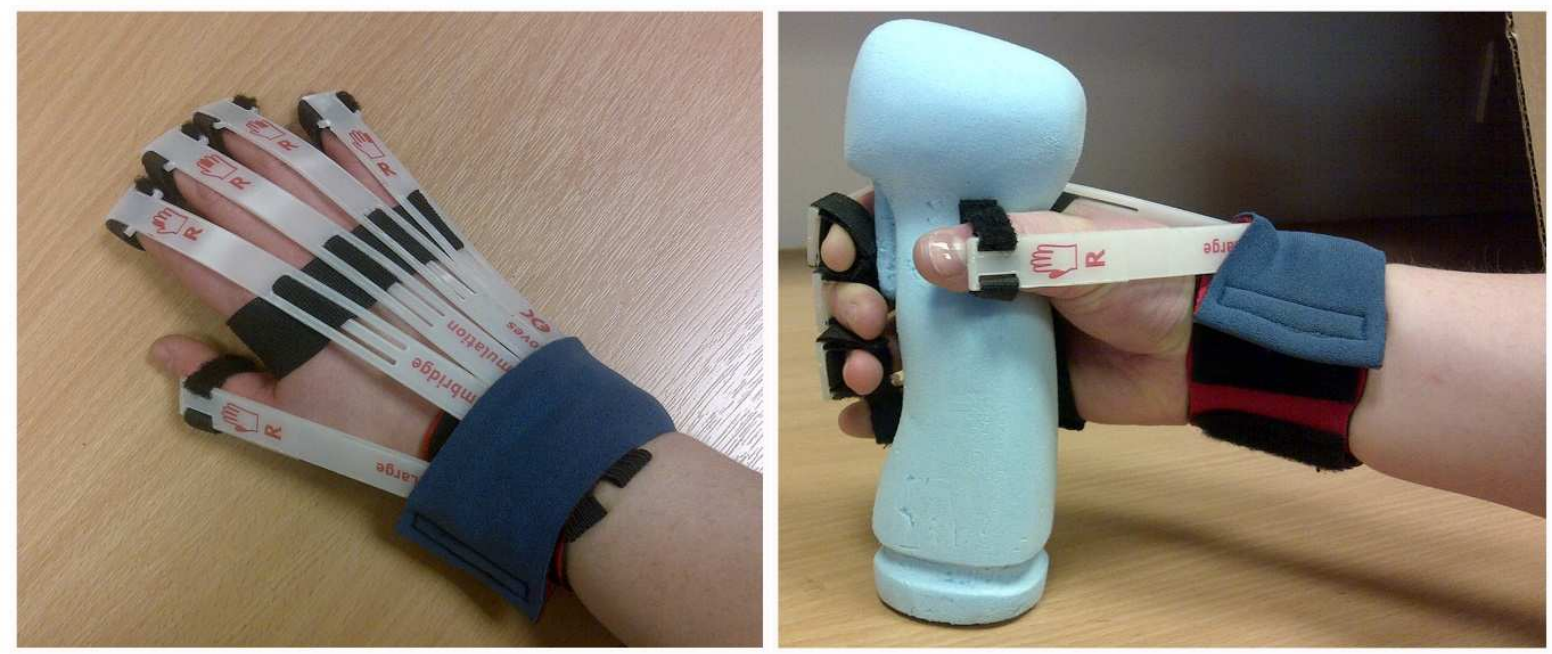

Figure 6. Simulation Gloves- The specifically designed gloves restricted movement in the hand fingers and wrist, allowing empathy with the elderly demographic.

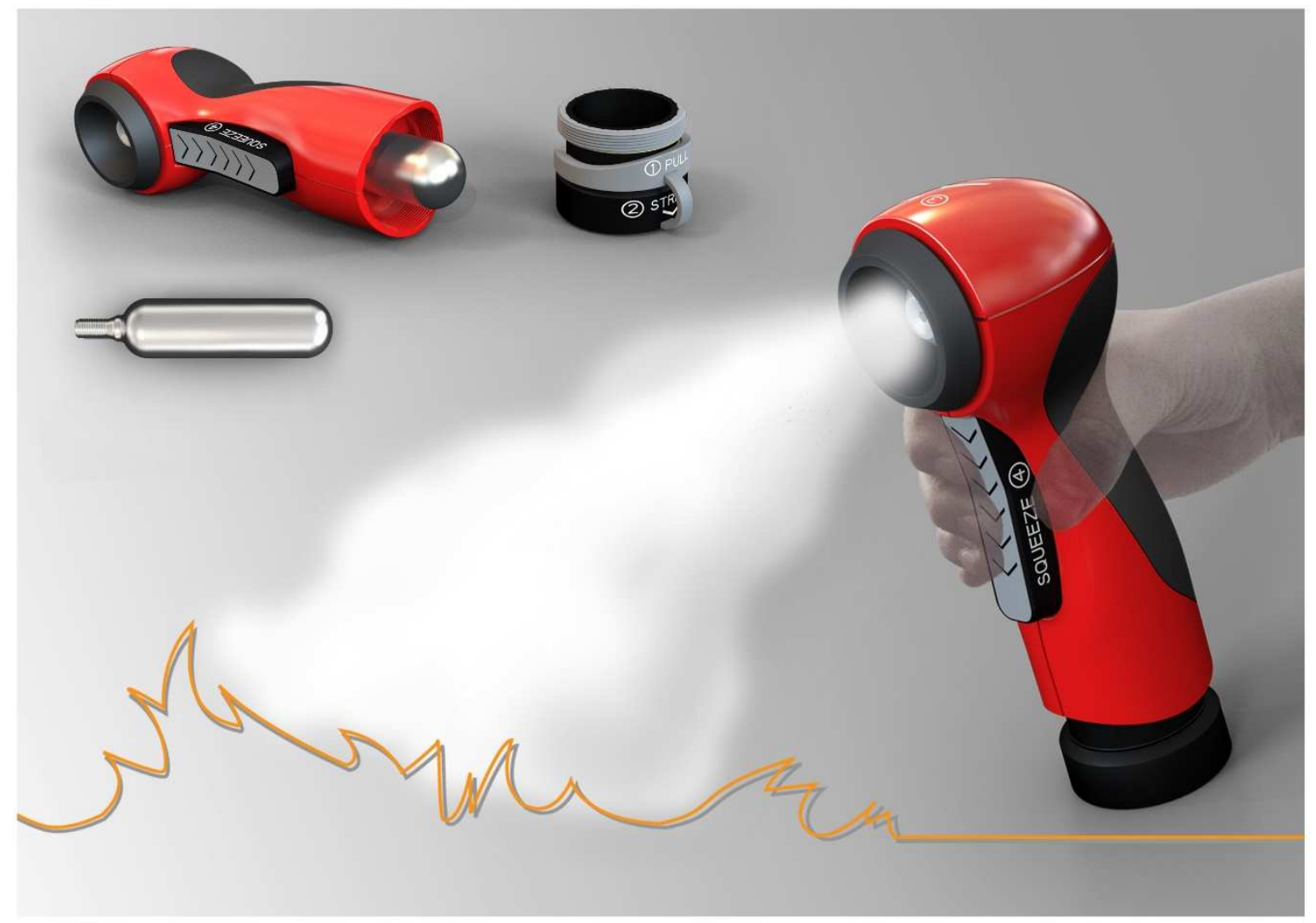

Figure 7. Redesigned Fire Extinguisher Concept 